\section{Los edificios modernos y sus efectos sobre la salud}

Un nuevo tipo de edificación ha surgido en nuestro medio en los últimos 30 años: el edificio sellado cuyo ambiente interno se mantiene homogéneo por medio de aparatos que regulan la humedad y la temperatura. Estos ambientes laborales modernos, donde millones de personas pasan diariamente largas horas, pueden afectar a la salud como consecuencia de los individuos que los ocupan, de las actividades que se llevan a cabo en su interior, de los contaminantes externos que penetran en ellos y de sus materiales, plantas, mobiliarios y sistemas de ventilación. En la mayor parte de los casos, las condiciones ambientales están bajo la vigilancia de uno o dos técnicos que no tienen manera de medir las concentraciones de sustancias contaminantes y que tienen poco contacto con las personas que ocupan el edificio.

Este nuevo ecosistema no industrial propio de los complejos de oficinas ha generado una serie de problemas de salud -las llamadas "enfermedades asociadas con los edificios", algunas de las cuales tienen carácter general y otras carácter específico- que abarcan desde las rinitis hasta algunas afecciones infecciosas, inmunológicas, alérgicas o irritativas. El hacinamiento y la mala circulación del aire facilitan la propagación de agentes infecciosos. En algunos casos un mismo agente puede producir un cuadro grave o relativamente inocuo. Sirven de ejemplo dos enfermedades provocadas por la bacteria Legionella pneumophilia: la enfermedad de los legionarios, que suele poner en peligro la vida, y la fiebre Pontiac, que apenas produce síntomas catarrales leves. La neumonitis por hipersensibilidad también abarca un amplio espectro de manifestaciones, aunque las más comunes son tos, disnea, anomalías de la función pulmonar y alteraciones radiográficas. En raras ocasiones se han producido brotes de asma en edificios de oficinas, sin que se haya podido identificar el agente causal. La exposición al polvo, a ciertas plantas y a algunos alérgenos transportados pasivamente pueden presentarse en cualquier edificio habitado $y$, según ciertas pruebas efectuadas con fines de investigación, las emanaciones de las fotocopiadoras y las hojas de papel para calcar pueden producir reacciones de hipersensibilidad, entre ellas urticaria, edema laríngeo y faringitis. Diversos materiales no alérgenos, como las fibras de vidrio artificial, pueden causar dermatitis, conjuntivitis e irritación de vías respiratorias bajas. Por otra parte, el llamado envenenamiento por monóxido de carbono oculto - producido por la entrada del humo de automóviles y del humo de tabaco- puede elevar la carboxihemoglobina en sangre lo suficiente para causar deterioro cognoscitivo, alteraciones de la atención, cefalea y mareos. La acumulación de dióxido de nitrógeno y de formaldehído también puede conducir a síntomas respiratorios, aunque aún no se ha documentado ningún brote relacionado con la exposición a esta última sustancia.

Existen también algunas "enfermedades asociadas con los edificios" que no son de carácter específico y que se presentan con mayor frecuencia que los brotes provocados por agentes conocidos. La explicación en estos casos está dada por 1) la gran variedad en el umbral de sensibilidad de cualquier población, 2) el amplio espectro de respuestas inducidas por cualquier sustancia o material, y 3) la variabilidad de los niveles de exposición dentro de un complejo de oficinas. Hay suficientes pruebas indirectas de los posibles estímulos causales para poder emitir las siguientes recomendaciones: mantener un volumen de aire exterior de más de 10 litros por segundo por persona; escoger los muebles y materiales de construcción y decoración que despidan menos sustancias nocivas; llevar buenos servicios de mantenimiento y limpieza; evitar el uso de materiales que alberguen microbios o acáridos.

Las personas que trabajan en edificios de oficinas constituyen más de la mitad de la fuerza de trabajo de países industrializados y un porcentaje importante y cada vez mayor de la de países en desarrollo. En vista de ello y de la escasez de conocimientos sobre las afecciones que pueden ser ocasionadas por este tipo de ambiente, hay una necesidad urgente de efectuar investigaciones al respecto. Es imprescindible hacer estudios de sensibilidad a sustancias contaminantes, aisladas y en combinación, y poner a prueba las intervenciones contempladas mediante buenos ensayos basados en una definición de casos estandarizada, encuestas a los empleados y técnicas para medir las concentraciones de contaminantes ambientales. (Menzies D, Bourbeau J. Building-related illnesses. New Engl J Med 1997; 337(21):1524-1531). 
Los peligros de consumir suplementos
de carotenoides para prevenir el cáncer

Algunos científicos afiliados con la Agencia Internacional de Investigación del Cáncer (IRACA) de la OMS han emitido una advertencia contra el consumo de suplementos dietéticos a base de sustancias derivadas de frutas y verduras frescas, y particularmente los comprimidos a base de carotenoides, para la prevención del cáncer. Según afirmaron estos expertos, las frutas y verduras frescas son la primera línea de defensa contra la enfermedad.

En las dos últimas décadas numerosos estudios epidemiológicos en distintos países han demostrado que una dieta rica en frutas y vegetales reduce el riesgo de padecer de cáncer. Los resultados de estos estudios han dado pie a la creencia muy difundida de que los constituyentes de las plantas, tales como los carotenos y el caroteno beta en particular, pueden proteger contra el cáncer.

En diciembre de 1997, un grupo de 23 científicos procedentes de 10 países se reunió en Lyon, Francia, para evaluar todos los estudios que se han publicado sobre los efectos de los carotenos en la salud. Examinaron, entre otros, los resultados de ensayos clínicos en que se administraron altas dosis de caroteno beta para reducir la incidencia del cáncer y la mortalidad que lo acompaña en poblaciones de personas sanas. Se llegó a la conclusión de que ningún estudio reveló un efecto protector beneficioso. Más bien, la administración de altas dosis de caroteno beta a fumadores aumentó el riesgo de cáncer de pulmón y la mortalidad por enfermedades cardiovasculares.

El grupo de expertos declaró que antes de poder promover la distribución poblaciones de caroteno beta y otros carotenoides como agentes preventivos antineoplásicos es necesario tener mucha más información sobre la forma en que estas sustancias influyen sobre los procesos que llevan a la formación de un tumor. En este momento todo parece señalar que el consumo de frutas y verduras frescas es una medida más eficaz para la prevención del cáncer que el consumo de uno o varios de sus constituyentes en forma de suplementos dietéticos. (World Health Organization. Carotenoid pills should not be promoted for cancer prevention. Press release WHO/4, 12 January 1998).

\section{Ventajas y desventajas del tratamiento antirretrovírico para la infección por VIH}

A pesar de que en los últimos meses se han presenciado adelantos importantes y de gran promesa contra la infección por el virus de la inmuno- deficiencia humana (VIH), ahora se empiezan a apreciar algunas de las limitaciones del tratamiento antirretrovírico. La esperanza de poder erradicar la carga vírica en pacientes infectados mediante el tratamiento temprano y sostenido con medicamentos antirretrovíricos data desde 1996, cuando se pensaba que los reservorios celulares del VIH tenían una vida media corta y que eran accesibles con los fármacos modernos. Actualmente se sabe que en pacientes sin concentraciones detectables de ácido ribonucleico (ARN) de VIH existe una pequeña población de linfocitos CD4 en reposo que tienen integrado ácido desoxirribonucleico (ADN) provírico capaz de replicarse y cuya vida media es de varios meses o incluso años. No obstante, el tratamiento temprano del paciente puede ser importante por razones ajenas a la erradicación del virus. Está demostrado que ayuda a conservar la actividad anti-VIH de los linfocitos CD4, la cual se encuentra gravemente disminuida en pacientes con enfermedad progresiva. En teoría, la conservación de esta actividad puede a la larga conducir a la supresión completa del virus, posiblemente aun después de descontinuar el tratamiento antirretrovírico.

Según datos preliminares arrojados en 1996 por un ensayo clínico de fase 2 , hasta $90 \%$ de los pacientes con infección crónica por VIH y en tratamiento con zidovudina y lamivudina (ambos inhibidores de la transcriptasa inversa) más indinavir (inhibidor de proteasas) alcanzaron concentraciones plasmáticas no detectables de ARN de VIH durante las 24 semanas que duró el seguimiento. Esta combinación de fármacos, que pronto se convirtió en el tratamiento estándar de pacientes con enfermedad moderada o avanzada, no solo suprime la carga vírica, sino que permite un aumento temprano muy notable de los linfocitos auxiliares CD4 en la circulación, aunque no se sabe si ello representa la formación de linfocitos nuevos o la redistribución de células previamente atrapadas en los tejidos linfáticos.

Pese a estos adelantos, sigue habiendo factores que limitan la consecución de buenos resultados a largo plazo. En un protocolo de investigación (denominado ACTG 320), la combinación de zidovudina, lamivudina e indinavir no suprimió la carga vírica detectable en plasma en $60 \%$ de los pacientes con enfermedad avanzada. Lo mismo sucedió en $50 \%$ de los pacientes tratados con un régimen a base de indinavir o ritonavir. Debido a la frecuencia de resistencia cruzada a los tres tipos de medicamentos antirretrovíricos (los inhibidores nucleosídicos y no nucleosídicos de la transcriptasa inversa y los inhibidores de las proteasas), el fracaso con un régimen limita las futuras opciones terapéuticas. Esto implica la necesidad de desarro- 
llar nuevos fármacos, proceso que actualmente avanza con lentitud.

Acatar fielmente el tratamiento contra VIH no siempre es fácil y en algunos casos resulta imposible. Los regímenes existentes suelen ser complejos y exigen observar ayunos y un horario complicado, según el tipo de tratamiento. También son frecuentes los efectos secundarios y la interacción con otros medicamentos. Algunos efectos indeseables son hiperlipemia, hiperglicemia, resistencia a la insulina y la redistribución poco estética de la grasa corporal. Estos efectos ponen en tela de juicio la inocuidad de los tratamientos más novedosos cuando se usan por períodos prolongados. Por último, el acceso de pacientes con VIH a los servicios de atención médica sigue siendo limitado y poco equitativo debido a su gran carestía y al hecho de que la mayor parte de los afectados son personas de escasos recursos. (Volberding PA, Deeks SG. Antiretroviral therapy for HIV infection: promises and problems. JAMA 1998;279(17):1343-1344).

\section{Prueba rápida para investigar el origen del dolor torácico agudo}

La evaluación del paciente que llega a la sala de urgencias con dolor torácico suele ser lenta y costosa y raras veces conduce a un diagnóstico seguro. Un grupo de investigadores alemanes efectuó un ensayo prospectivo en 773 pacientes con el fin de evaluar la utilidad de las mediciones de troponina $\mathrm{T}$ e I para determinar el origen de este tipo de dolor. Todos los pacientes habían tenido dolor torácico de menos de 12 horas de duración sin que se detectara ninguna elevación del segmento ST en el electrocardiograma. Se hicieron como mínimo dos determinaciones de troponina T e I usando pruebas cualitativas de alta sensibilidad a base de anticuerpos monoclonales específicos. La primera prueba se hizo a la llegada del paciente a la emergencia y la segunda al cabo de 4 horas o más, de tal manera que una de las muestras se obtuvo un mínimo de 6 horas después del inicio del dolor.

Se obtuvieron resultados positivos a la troponina $\mathrm{T}$ en 123 pacientes $(16 \%)$ y a la troponina I en $171(22 \%)$. De 47 pacientes que estaban sufriendo infarto progresivo del miocardio, 44 (94\%) tuvieron positividad a la troponina T y $47(100 \%)$ a la troponina I. De 315 pacientes con angina inestable, 70 (22\%) dieron resultados positivos a la troponina $\mathrm{T} y$ $114(36 \%)$ a la troponina I. Durante los 30 días de seguimiento se produjeron 20 defunciones y 14 infartos del miocardio sin defunción. Las troponinas $\mathrm{T}$ e I resultaron ser indicadores buenos e independientes de un trastorno cardíaco. Solamente 1,1\% de los sujetos con detección de troponina $\mathrm{T}$ y $0,3 \%$ de los sujetos con troponina I tuvieron un problema coronario.

En resumen, las pruebas de cabecera para la detección de troponinas de origen cardíaco tienen gran sensibilidad para la detección temprana de lesión de las células del miocardio en pacientes con síndromes coronarios agudos. Los resultados negativos se asocian con un riesgo bajo de lesión cardíaca y permiten dar de alta rápido y sin peligro a pacientes con dolor torácico agudo que acuden a los servicios de urgencia. (Hamm CW, Goldmann BU, Heeschen C, Kreymann G, Berger J, Meinertz T. Emergency room triage of patients with acute chest pain by means of rapid testing for cardiac troponin T or troponin I. New Engl J Med 1997;337(23): 1648-1653).

\section{La reproducción asistida: un dilema ético y legal}

La fecundación in vitro y la transferencia de gametos a la trompa de Falopio representan nuevas tecnologías reproductivas que han ayudado a procrear a cientos de miles de parejas con problemas de fertilidad. En ellas se refleja el afán del ser humano por conquistar territorios desconocidos en el campo de las ciencias y la tecnología, movido por una curiosidad que traspasa los límites de lo meramente necesario y que es rasgo distintivo de su especie. No es de extrañar que la creatividad científica del hombre cobre su máximo impulso en el caso particular de la reproducción, si se considera que esta representa su única posibilidad de proyectarse más allá de su propia vida y, en ese sentido, de saborear cierta medida de eternidad. De ahí la buena acogida que tuvieron en los años setenta las dos técnicas arriba mencionadas, que pronto pasaron al dominio público, dotando a las personas de la capacidad para intervenir en los procesos germinales de su propia existencia. Pero con ellas se crearon nuevos interrogantes y toda suerte de polémicas filosóficas, existenciales, religiosas, legales y biológicas. La duda subyacente es si todo lo que es posible desde el punto de vista científico y tecnológico es también moralmente aceptable o beneficioso para la humanidad. La respuesta no radica en la biología exclusivamente, sino en un aporte de opiniones y conocimientos multidisciplinario.

Las técnicas que están suscitando mayor controversia son la crioconservación del producto de la fecundación cuando apenas cuenta con tres a cuatro células (con el fin de reimplantarlo en la madre en un momento futuro); el empleo de técnicas de diagnóstico genético en embriones que aún no están implantados, y la donación y adopción de gametos 
para beneficio de parejas heterosexuales infértiles. Todas estas técnicas colocan al hombre en el dilema de tener que decidirse por aprender de la naturaleza y tratar de conquistarla, o por cerrarse a cualquier conocimiento nuevo movido por el prejuicio, el temor o la convicción moral o religiosa. Las dos primeras técnicas - la crioconservación de la mórula y el diagnóstico genético antes de la implantación-generan la problemática central de tener que distinguir entre el estado de persona o de persona en potencia y el de conceptus en división. De la postura que se elija dependerán las leyes sobre la realización de investigaciones con tejidos embrionarios y la autoridad llamada a definir sus límites. Por otra parte, cada vez se ensancha más el concepto de familia y se borran los límites entre paternidad y maternidad biológica y social. Dónde empiezan y terminan los derechos del progenitor (donador de gametos) y del padre o la madre (receptor de gametos) es un nuevo campo de polémica. Y con el descubrimiento de técnicas reproductivas más complejas sobrevendrá la necesidad de contestar nuevos interrogantes y de reflexionar más profundamente sobre la relación del ser humano con la naturaleza, su postura ante Dios y el universo y las consecuencias morales, éticas y legales de dar rienda suelta a su afán de descubrimiento e innovación. En última instancia, el ser humano se verá obligado a determinar si su inteligencia y espíritu de aventura, manifestados desinhibidamente, sean el compás certero que algún día lo lleve a descubrir la naturaleza de la esencia vital de donde emana todo cuanto existe. (Zegers-Hochschild F. Dilemas de la reproducción asistida. Cad Saude Publ 1998;14(supl. 1):7-13).

\section{Centellografía mamaria para diagnosticar el cáncer de mama}

Cada año se diagnostican en los Estados Unidos de América alrededor de 180000 casos nuevos de cáncer de mama, que es la primera causa de mortalidad por cáncer no pronosticable en ese país. La detección de lesiones tempranas depende principalmente del autoexamen mamario acompañado del examen físico por un profesional de la salud y mamografía. La experiencia acumulada a través de los años ha revelado, sin embargo, que esta última técnica no tiene la confiabilidad que en un principio se le atribuía en lo que concierne al diagnóstico de cáncer. En algunos casos la lesión no se visualiza y en otros no se puede distinguir con facilidad entre lesiones benignas y malignas, por no observarse las calcificaciones que son un signo casi patognomónico de malignidad. El valor predictivo de la mamografía en los Estados Unidos es de alrededor de 15 a $30 \%$ cuando se compara con los resultados de la biopsia, que sirve de "estándar de oro". En casos de incertidumbre se recurre a uno de dos tipos de biopsia: la que se efectúa con aguja fina (fine needle aspiration) y la que se hace con aguja gruesa (core biopsy). Ambas, en mayor o menor medida, son técnicas invasoras que dejan cicatrices y en ocasiones deformidades mamarias. Tienen el inconveniente adicional de interferir con la interpretación de mamografías posteriores, que también se ve menoscabada por factores tales como la densidad excesiva del tejido glandular, las secuelas de la radioterapia, la lactancia materna y la ubicación profunda de la lesión.

El 99mTc-Sestamibi, compuesto catiónico usado ampliamente en cardiología nuclear, ha sido objeto de interés reciente por su posible aplicación para la detección de tumores mamarios. Este compuesto penetra en las células por difusión pasiva por las membranas plasmática y mitocondrial, proceso que se ve determinado por la intensidad del flujo sanguíneo local. Un grupo de investigadores argentinos estudió los resultados obtenidos con esta técnica en 17 mujeres mayores de 26 años sin antecedentes quirúrgicos mamarios y con tumores de mama (palpables o no palpables) diagnosticados por mamografía en las últimas 8 semanas. Doce de las pacientes tenían lesiones con características de cáncer, una tenía una lesión ambigua y cuatro tenían lesiones que parecían benignas.

La centellografía mamaria reveló 14 lesiones cancerosas y tres benignas. Aplicada en la región axilar, la centellografía suscitó la sospecha de metástasis regionales en cinco casos que habían parecido normales en la mamografía. El examen anatomopatológico reveló dos casos positivos falsos y ningún caso negativo falso, a la vez que mostró metástasis axilares en ocho pacientes, entre las cuales figuraban las cinco detectadas con la centellografía. El análisis estadístico reveló una sensibilidad de $82,3 \%$; una especificidad de $76,9 \%$; un valor predictivo positivo de $85,7 \%$ y un valor predictivo negativo de $14,3 \%$. Aunque el número de pacientes estudiadas fue pequeño, la centellografía mamaria con 99m Tc-Sestamibi promete ser una técnica eficiente como complemento de la mamografía para la detección de neoplasias mamarias malignas. (Croci A, Corbeta J, Vivante H, Orsi H, Romanella J. Centellografía mamaria en el diagnóstico del cáncer de mama. Prensa Med Argent 1998;85(1):33-41). 